\title{
Trends in socioeconomic inequalities in risk of sudden infant death syndrome, other causes of infant mortality, and stillbirth in Scotland: population based study
}

\author{
OPEN ACCESS
}

\author{
Angela M Wood lecturer ${ }^{1}$, Dharmintra Pasupathy NIHR clinical lecturer ${ }^{2}$, Jill P Pell professor ${ }^{3}$, \\ Michael Fleming statistician ${ }^{4}$, Gordon C S Smith professor ${ }^{5}$
}

'Department of Public Health and Primary Care, University of Cambridge, Cambridge CB1 8RN, UK; ${ }^{2}$ Women's Health Academic Centre, King's Health Partners, King's College London, London SE1 7EH; ${ }^{3}$ Public Health Unit, University of Glasgow, Glasgow G12 8RZ; ${ }^{4}$ Information Services Division, NHS National Services Scotland, Edinburgh EH12 9EB; ${ }^{5}$ Department of Obstetrics and Gynaecology, NIHR Biomedical Research Centre, University of Cambridge, Cambridge CB2 0SW

\begin{abstract}
Objectives To compare changes in inequalities in sudden infant death syndrome with other causes of infant mortality and stillbirth in Scotland, 1985-2008

Design Retrospective cohort study.

Setting Scotland 1985-2008, analysed by four epochs of six years

Participants Singleton births of infants with birth weight $>500 \mathrm{~g}$ born at 28-43 weeks' gestation.

Main outcome measures Sudden infant death syndrome, other causes of postneonatal infant death, neonatal death, and stillbirth. Odds ratios expressed as the association across the range of seven categories of Carstairs deprivation score.
\end{abstract}

Results The association between deprivation and the risk of all cause stillbirth and infant death varied between the four epochs $(P=0.04)$. This was wholly explained by variation in the risk of sudden infant death syndrome $(P<0.001$ for interaction). Among women living in areas of low deprivation, there was a sharp decline in the rate of sudden infant death syndrome from 1990 to 1993 . Among women living in areas of high deprivation, there was a slower decline in sudden infant death syndrome rates between 1992 and 2004. Consequently, the odds ratio for the association between socioeconomic deprivation and sudden infant death syndrome increased from 2.04 (95\% confidence interval 1.53 to 2.72 ) in $1985-90$, to 7.52 (4.62 to 12.25) in 1991-6, and 9.50 (5.46 to 16.53 ) in $1997-2002$ but fell to 1.78 (0.87 to 3.65 ) in 2002-8. The interaction remained significant after adjustment for maternal characteristics.

Conclusion The rate of sudden infant death syndrome declined throughout Scotland in the early 1990s. The decline had a later onset and was slower among women living in areas of high deprivation, probably because of slower uptake of recommended changes in infant sleeping position. The effect was to create a strong independent association between deprivation and sudden infant death syndrome where one did not exist before.

\section{Introduction}

Stillbirths and infant deaths are major contributors to the overall global burden of mortality. ${ }^{1}$ In the United Kingdom, stillbirth (delivery of a infant showing no signs of life at or after 24 weeks) affects about one in 200 potentially viable pregnancies ${ }^{2}$ and infant death (death of a infant in the first year of life) affects about one in 200 live births. ${ }^{3}$ It is well established that stillbirth and infant death are both more common among women of low socioeconomic status. ${ }^{4}$ Hence, a potential strategy for affecting overall rates of stillbirth and infant death is to deal with the environmental determinants of inequalities in maternal and family health.

The exemplar for affecting population rates of these losses is sudden infant death syndrome. Studies in the late 1980s and early 1990s found associations between sudden infant death syndrome and infant sleeping position. ${ }^{5-9}$ Dissemination of this information by the media and in public health campaigns (such as the "Back to Sleep" campaign in the UK) were followed by sharp declines in the rates of sudden infant death syndrome in many high income countries. ${ }^{10}$ A detailed study of sudden infant death syndrome and liveborn control infants suggested that the association between sudden infant death syndrome and socioeconomic status was markedly different before and after the recognition of the importance of sleeping position. ${ }^{11}$ There was, however, no longitudinal information and no information on changes in the nature of the relations between socioeconomic status and sudden infant death syndrome and other causes of infant death and stillbirth. We analysed nationally collected data from Scotland to characterise the relation between 
socioeconomic deprivation and sudden infant death syndrome, other causes of infant death, and stillbirth and to determine whether these relations varied during 1985-2008.

\section{Methods}

\section{Study population}

We linked three national registries of Scottish data: the Scottish Morbidity Record 02, a register of clinical and demographic characteristics and outcomes of all patients discharged from Scottish maternity hospitals; the Scottish Stillbirth and Infant Death Survey, a register of classification of all stillbirths and neonatal deaths in Scotland; and computerised birth and death registration records from the General Register Office. Approval for the record linkage was provided by the privacy advisory committee of the Information Services Division of the National Health Service (NHS) Scotland. To allow comparability across the range of years studied, we focused on singleton births at or after 28 weeks' gestation.

\section{Definition of stillbirth and infant mortality}

Stillbirth was defined as an infant born showing no signs of life. These were subgrouped into those in which intrauterine fetal death was known to have occurred during labour (intrapartum stillbirth) and other stillbirths (antepartum). Neonatal death was defined as death of a liveborn infant in the first four weeks of life. Antepartum stillbirth and neonatal death were ascertained from the Scottish Stillbirth and Infant Death Survey. The cause of stillbirth and neonatal death was coded with a modification of the Wigglesworth classification ${ }^{12}{ }^{13}$ by a single medically qualified individual (the Scottish coordinator) in the information services division of the NHS. In the present analysis antepartum stillbirth was subgrouped into congenital, other explained, and unexplained. Congenital abnormality was defined as "any structural or genetic defect incompatible with life or potentially treatable but causing death." Antepartum stillbirths from antepartum haemorrhage, pre-eclampsia/eclampsia, mechanical issues (such as cord prolapse), maternal disorder (such as diabetes, infection), or other specified causes were classified as explained antepartum stillbirth. All other stillbirths were classified as unexplained. Unexplained stillbirths were further subclassified into those in which the baby was small for gestational age (defined as birth weight in the lowest 10th, corrected for sex and gestational age) and those in which the baby was not small for gestational age. Intrapartum stillbirth or neonatal death was initially classified by the presence of a lethal structural anomaly (defined as above) and the others were subdivided by gestational age into preterm ( $<37$ weeks) and term ( $\geq 37$ weeks) deaths.

Postneonatal infant death was defined as death between day 29 and the first completed year of life and was ascertained from the General Register Office registry. The cause of postneonatal infant death was coded with the ICD (international classification of diseases) diagnostic code in the principal position. Postneonatal infant deaths were classified as caused by congenital abnormality, infection, other, or sudden infant death syndrome. Table 1 shows the diagnostic codes used for classification $\Downarrow$. In Scotland a diagnosis of sudden infant death syndrome can be written on a death certificate only after a thorough investigation of the circumstances of the death. ${ }^{14} \mathrm{~A}$ previous detailed study of 201 deaths attributed to sudden infant death syndrome on Scottish death certificates in 1992-5 reported that standard diagnostic criteria were met in nearly all cases. ${ }^{15}$

\section{Definition of maternal and obstetric characteristics}

Socioeconomic deprivation was measured with the Carstairs socioeconomic deprivation score. This scoring system is based on census data on car ownership, unemployment, overcrowding, and social class within postcode sectors of residence, which contain an average of 1600 residents. The deprivation scores were then used to categorise women into seven categories (1=least deprived, $7=$ most deprived). This scoring method was devised to explain area variation in health indicators and correlates well with material disadvantage. ${ }^{16}$ Information on parity, height, and marital status were as reported at the time of the first antenatal visit. Maternal age was defined as the mother's age on the day she delivered. Hospital throughput was defined as the total number of births recorded in the Scottish Morbidity Record 02 database for the given hospital over the given year. Smoking status was defined as current, past, or never at the time of the first antenatal visit and was available from 1992 onwards.

\section{Sensitivity analyses}

To determine whether results could be affected by systematic changes in the classification of deprivation over the time period, we determined the relation between deprivation category and maternal age less than 20 over the study period, and we repeated key analyses using low maternal age as a proxy of deprivation. A proportion of records in both the Scottish Stillbirth and Infant Death Survey and General Register Office death certificate registries did not link to Scottish Morbidity Record 02 records. Hence, key analyses were repeated with inclusion of these records. Finally, as maternal smoking status was recorded only from 1992 onwards, key analyses were repeated confined to the years when data on smoking were available.

\section{Statistical analyses}

Continuous variables were summarised by the median and interquartile range and comparisons made by the Kruskal-Wallis test. Univariate comparisons of dichotomous data were made with the $\chi^{2}$ test and $\chi^{2}$ test for trend, as appropriate. The risk of events was modelled with logistic regression. Socioeconomic deprivation was treated as a continuous variable in all regression models. Odds ratios are presented for a six category change in socioeconomic deprivation to represent a move from the lowest to the highest socioeconomic deprivation group. Missing data on maternal age, parity, height, marital status, and smoking (for records from 1992 onwards) were handled with multiple imputation by chain equations. ${ }^{17}$ Five imputations were created by using a set of appropriate imputation models constructed from all covariates and outcome variables, stratified by year epochs. Results were robust to different imputation approaches (including using categories of deprivation, maternal age, height, and parity to relax linear assumptions in imputation models; ignoring stratification by epoch; increasing the number of imputations to 20; and using predictive mean matching rather than drawing imputations from the posterior distributions). The significance of interactions was assessed with the Wald test. Clustered analyses at maternal level were performed on the logistic models to account for repeated deliveries to the same individual. The $\mathrm{P}$ values for all the hypotheses were two sided, with significance set at $\mathrm{P}<0.05$. All analyses were performed with Stata, version 10.1, software (Stata, TX, US).

\section{Results}

The linked Scottish Morbidity Record 02, Scottish Stillbirth and Infant Death Survey, and General Register Office databases 
contained 1386967 eligible records of singleton pregnancies with a total of 11058 stillbirths and infant deaths in Scotland in 1985-2008. Figure 1 shows the selection of the cohort and denominators for each analysis $\Downarrow$. The maternal, fetal, and obstetric characteristics and rates of stillbirth and infant death of the study cohort varied by the socioeconomic deprivation category (table $2 \Downarrow$ ). High socioeconomic deprivation score was positively associated with parity, smoking, and preterm birth and was negatively associated with maternal age, height, and marital status. There was a linear association between rates of antepartum stillbirth, intrapartum stillbirth, neonatal death, and postneonatal infant death and socioeconomic deprivation score.

We then performed logistic regression analysis of the association between socioeconomic deprivation category and each of the major causes of death and assessed the effect of statistical adjustment for maternal characteristics, smoking status, and gestational age. This analysis was confined to births from 1992 onwards as data on smoking were not obtained in the earlier years. Univariate analysis of antepartum stillbirth showed that socioeconomic deprivation was associated with an increased risk of stillbirth from a congenital anomaly, other explained stillbirths, and unexplained stillbirths where the baby was small for gestational age (table $3 \Downarrow$ ). The association with losses from congenital anomaly was only mildly attenuated by adjustment for maternal factors, but maternal factors accounted for $50 \%$ or more of the other associations. In contrast, there was no association between deprivation and unexplained stillbirth when the baby was not small for gestational age. Univariate analysis of intrapartum stillbirth and neonatal death showed generally weaker associations with socioeconomic deprivation and none persisted in multivariate analysis. Univariate analysis of postneonatal infant death showed the strongest overall association with socioeconomic deprivation. This was largely because of sudden infant death syndrome but also because of a moderately strong association with death from congenital anomaly. The association between socioeconomic deprivation and postneonatal infant death from congenital anomaly, however, was virtually unaltered by statistical adjustment for maternal characteristics, whereas the association with sudden infant death syndrome was reduced by more than half.

We then compared the associations across the four epochs: 1985-90, 1991-6, 1997-2002, and 2003-8. The association between socioeconomic deprivation and the risk of all cause stillbirth and infant death varied across the four epochs in the univariate (table $4 \Downarrow, \mathrm{P}=0.04$ for interaction) and multivariate (table $5 \Downarrow, P=0.02$ for interaction) analyses. When analysed by cause of death, there was strong evidence that the association with sudden infant death syndrome varied across these four epochs $(\mathrm{P}<0.001$ for interaction), but no strong evidence to support an interaction for any other causes of death. Moreover, there was no interaction between epoch and socioeconomic deprivation when the outcome was stillbirth, neonatal death, or postneonatal death, excluding sudden infant death syndrome (unadjusted $\mathrm{P}=0.32$ ). The unadjusted odds ratios for sudden infant death syndrome for a change from the lowest to the highest deprivation groups rose from about 2.0 in 1985-990, to 7.5 in 1991-6, and 9.5 in 1997-2002. Furthermore, multivariate analysis showed no independent association between deprivation and the risk of sudden infant death syndrome in 1985-990, but about a fourfold risk after adjustment for maternal characteristics in the subsequent 12 years.

The annual rate of sudden infant death syndrome fell in Scotland in the 1990s (fig $2 \Downarrow$ ). When studied by year of birth, both the timing of onset and rate of decline varied in relation to socioeconomic deprivation. Among women living in areas of low deprivation, the decline started among infants born in 1990 and continued to fall sharply until 1993. Among women living in areas of high deprivation, the decline started among infants born in 1992 and continued to fall over the next 10-15 years.

We performed several sensitivity analyses. Firstly, we examined whether a similar interaction was observed between epoch and deprivation when we used maternal age $<20$ as a proxy of deprivation. The unadjusted odds ratio (95\% confidence interval) for sudden infant death syndrome associated with maternal age less than 20 was 1.99 (1.61 to 2,45) in 1985-90, 3.15 (2.32 to 4.30) in 1991-6, 3.55 (2.51 to 5.04) in 1997-2002, and 2.52 (1.54 to 4.14 ) in 2003-8. As with deprivation category, the association with maternal age $<20$ also varied significantly across the four epochs ( $\mathrm{P}=0.01$ for interaction). We also sought to determine whether the association between low maternal age and living in an area of high deprivation changed over the study period. With maternal age $<20$ as the outcome, the association for a change from the lowest to the highest deprivation category was 6.23 (5.97 to 6.50) in 1985-90, 5.85 (5.59 to 6.12) in 1991-6, 6.04 (5.77 to 6.34) in 1997-2002, and 4.97 (4.73 to 5.21) in 2003-8. Hence, the association between area of socioeconomic deprivation and low maternal age remained relatively consistent over the study period. The Scottish Stillbirth and Infant Death Survey included records on 404 antepartum stillbirths and 220 intrapartum stillbirths and neonatal deaths over the period that did not link to a Scottish Morbidity Record 02 record. The General Register Office database included 342 records of infant deaths of children born in Scotland over the period that did not link to a Scottish Morbidity Record 02 record (however, we were unable to exclude those unlinked records where delivery occurred before 28 weeks' gestation as gestational age at birth is not recorded on the General Register Office birth registry). These represented $7.0 \%$ and $11.2 \%$ of all eligible Scottish Stillbirth and Infant Death Survey and General Register Office records, respectively. We compared the unadjusted associations between socioeconomic deprivation category and each of the outcomes over the four time periods when the unlinked records were included (table $6 \Downarrow$ ) and the associations and interaction were similar. Finally, we wanted to determine whether the interaction could be determined in part by variation in maternal smoking. This was problematic as smoking data were collected only from 1992 - that is, around the time of the rapid changes in the rates of sudden infant death syndrome. Nevertheless, when we compared the association between deprivation category and sudden infant death syndrome in 1992-6, 1997-2002, and 2003-8, the adjusted odds ratios when smoking was included with the other maternal characteristics were 2.24 ( 0.65 to 3.37 ), 3.32 (1.78 to 6.18 ), and 0.60 (0.29 to 1.29$)$, respectively, and the variation over these three epochs was also highly significant ( $\mathrm{P}=0.002$ for interaction).

\section{Discussion}

The relation between socioeconomic deprivation and the risk of sudden infant death syndrome changed dramatically in Scotland over the period 1985-2008. There was a sharp decline in the rate of sudden infant death syndrome among women living in areas of low socioeconomic deprivation between 1990 and 1993. Among women living in areas of high socioeconomic deprivation, there was a much slower decline in the rate of sudden infant death syndrome between 1992 and 2004. When we modelled the risk of sudden infant death syndrome with logistic regression, there was about a twofold risk of sudden infant death syndrome across the range of deprivation in the period 1985-90, which was lost with adjustment for maternal characteristics. In the period 1991-2002, however, there was an 
up to 10-fold risk of sudden infant death syndrome across the range of deprivation. Moreover, there was still a significant association between deprivation and sudden infant death syndrome in the period 1991-2002 after adjustment for maternal characteristics. There were no comparable changes in the relation between deprivation and the risk of stillbirth, neonatal death, or other causes of postneonatal infant death.

We believe that the most plausible explanation for this pattern is slower dissemination of information about the risk of sudden infant death syndrome associated with prone sleeping position among families living in areas of high socioeconomic deprivation in the early 1990s. The consequences of this were to increase relative disparity in rates of sudden infant death syndrome and to create a strong and independent association between living in an area of high socioeconomic deprivation and sudden infant death syndrome where one did not previously exist.

\section{Other interpretations of pattern of change}

The change in the patterns observed could have been caused by variation in some other risk factor for sudden infant death syndrome. There are, however, several features of the analysis that suggest that this is unlikely. Firstly, the association between deprivation and sudden infant death syndrome in the 1990s was strong, with an odds ratio of up to 9.5 . The presence of a strong association makes confounding a less likely explanation for the results. Secondly, the association was transient: the odds ratios were increased in the middle two epochs but similar in the first and the last. Finally, it could be argued that the attenuation of the strength of the association in multivariate analysis is consistent with a confounding effect of one of the covariates in the model, though a significant association persisted in multivariate analysis. We believe, however, that the determinant of the increased strength of association with sudden infant death syndrome in 1991-2002 was failure to implement recommendations on infant sleeping position, a characteristic that we could not measure. It is plausible that this behaviour would correlate with the other maternal characteristics that we could measure. Hence, adjustment for these characteristics would be expected to attenuate the association between deprivation and sudden infant death syndrome, as they could act as a proxy measure of behaviour around infant sleeping position. A large scale case-control study from 12 European centres analysing sudden infant death syndrome between 1992 and 1996 described comparable associations with maternal sociodemographic factors, which were attenuated by $50 \%$ or more in multivariate analysis. ${ }^{18}$

\section{Impact of the "Back to Sleep" campaign}

These findings should not be interpreted as indicating that dissemination of information on the importance of infant sleeping position was either ineffective or harmful. This research and its dissemination were followed by abrupt declines in the rate of sudden infant death syndrome throughout the world. ${ }^{10}$ As rates of sudden infant death syndrome were higher among infants of deprived women, the total number of deaths prevented was greater among women living in areas of high deprivation. For example, if we compare 1985-90 with 2003-8, the reduction in absolute rates of sudden infant death syndrome was 8.9 per 10000 live births in the areas with lowest deprivation and 19.8 per 10000 live births in the areas of highest deprivation - that is, the absolute number of deaths prevented was higher in areas of high deprivation. The current observations, however, indicate that the impact of the research had a later onset and took longer to be maximally effective in areas of high deprivation. Hence, the recognition of the importance of infant sleeping position had similar potential to reduce rates of death across the whole range of deprivation but it was much slower in being effective in areas of high socioeconomic deprivation. This experience indicates that a component of any future campaigns to modify environmental risk factors for stillbirth and infant death should be the consideration of how the message might optimally be delivered to those living in areas of high deprivation.

Analysis of the annual rate of sudden infant death syndrome showed that it began to fall in 1990, the year before the public health campaign ("Back to Sleep") that advised against the prone sleeping position for infants. This could be interpreted as indicating that the fall in sudden infant death syndrome rates was not caused by changes in infant sleeping position. Detailed analysis of the timing of publication of the key research on sleeping position, however, is revealing. In 1988 a letter was published in the Lancet observing that all nine studies that had studied sleeping position had shown an association between prone sleeping position and sudden infant death syndrome. ${ }^{5}$ In March 1989, two papers published in the $B M J$ reported positive associations between sudden infant death syndrome and prone sleeping position (the data from both of these studies had been included in the 1988 Lancet letter). ${ }^{67}$ In July 1990, a case-control study from the UK showed an approximate ninefold risk of sudden infant death syndrome with prone sleeping position, ${ }^{8}$ and in February 1991, a case-control study from New Zealand reported a 3.5-fold risk. ${ }^{9}$ These findings led to the initiation of the "Back to Sleep" campaign in the UK in November 1991. If we examine the annual rates of death from sudden infant death syndrome in Scotland, the onset of the abrupt decline occurred in 1990 among women living in areas of low deprivation and in 1992 among women living in areas of high deprivation. The onset of the reduction in rates among women in areas of high deprivation in 1992 is consistent with this being a consequence of the 1991 campaign. We believe that the earlier onset of the reduction in rates among women living in areas of low socioeconomic deprivation is probably explained by dissemination of information on sleeping position from research studies, before the public health campaign. We searched two online databases of news articles (Factiva and Lexis) and identified articles reporting the findings of the 1990 BMJ paper in the Times, the Independent, and the Guardian and the story was also circulated by the news agency Reuters. All articles mentioned the association with sleep position. The patterns observed are consistent with the view that public health campaigns can be an effective means of changing behaviours associated with disease but also indicate that reliance on conventional media to promote such messages has the potential to lead to greater relative disparity.

\section{Limitations of the current study}

The data used in the present analysis have some important limitations. Firstly, we relied on data from death certificates to identify cases of sudden infant death syndrome. Some of deaths ascribed to sudden infant death syndrome could have other causes, and the definition of sudden infant death syndrome might have changed over the study period. A previous detailed study of 201 deaths attributed to sudden infant death syndrome on Scottish death certificates in 1992-5, however, found that standard diagnostic criteria were fulfilled in nearly all cases. ${ }^{15}$ Furthermore, the lack of interaction with other causes of postneonatal infant death suggests that changing patterns in the association between deprivation and sudden infant death syndrome were not explained by variation in the classification of the cause of postneonatal infant death over the time period. 
Secondly, we relied on postcode rather than individual level characteristics of patients to quantify socioeconomic deprivation. Moreover, information on key confounders was lacking. Smoking was documented only from 1992 onwards and was available only as a qualitative variable without information on number of cigarettes used. Furthermore, comparisons of self reported smoking status with cotinine concentrations in pregnancy have shown that self reported smoking under-reported true smoking by about $25 \% .{ }^{19}$ Smoking data were not available for 1985-90, but adjustment for the other maternal characteristics resulted in a loss of association between deprivation and sudden infant death syndrome in this period. Hence, the key findings of the present study are unlikely to have been affected by the quality of information available on maternal smoking.

Despite the subclassification of causes of stillbirth and infant death, some of the categories remain relatively broad. For example, we considered neonatal death associated with preterm delivery as a single group. In reality, this group constitutes several important subcategories, such as spontaneous preterm birth, preterm birth after preterm premature rupture of the fetal membranes, and medically indicated preterm birth. Further studies could examine the relations between deprivation and smaller subcategories of death. Furthermore, considerable changes have taken place in medical practice over the study period, such as the use of antenatal corticosteroids and postnatal surfactant. Both of these have substantially improved neonatal survival after birth at 24 weeks and beyond. We excluded births before 28 weeks to allow a valid comparison of rates of death across a 24 year period. It could be that the association between the risk of neonatal death and deprivation differs when infants born less than 28 weeks are included. The above questions, however, were outside the scope of the current study.

\section{Comparison with other studies}

A case-control study in the south west of England presented detailed information on the risk factors for sudden infant death syndrome in $2003-6 .{ }^{20}$ The study selected both random controls and controls among women who had high rates of conventional risk factors for sudden infant death syndrome (maternal smoking, high parity, low maternal age, and low social class or never employed). Mothers of infants dying from sudden infant death syndrome had an odds ratio for recent alcohol use of 14 compared with the high risk controls. We speculate that Carstairs deprivation category was quite strongly related to the sociodemographic characteristics associated with sudden infant death syndrome in 1991-2002. As supine sleeping position for infants has become more widely prevalent, however, the Carstairs deprivation category might be a less effective marker of the risk factors for the deaths that continue to occur, than, for example, alcohol use and unsafe co-sleeping.

\section{Associations between deprivation and stillbirth and other causes of infant death}

We also observed associations between deprivation category and other causes of stillbirth and infant death. The associations between deprivation and antepartum stillbirth of a small for gestational age infant and explained antepartum stillbirth were attenuated by $50-70 \%$ after adjustment for the other measured maternal characteristics. Given that degree of attenuation based on a limited series of maternal characteristics, a considerable proportion of the remaining association could probably be explained by unmeasured confounders. Similarly, deprivation was associated with intrapartum stillbirth and neonatal death from prematurity and with postneonatal infant deaths not ascribed to the three specific categories studied, but these associations were no longer significant in multivariate analysis. These findings indicate that much of the association between living in an area of high deprivation and stillbirth and infant death are explained by the risk profile of the women living in such areas. In contrast, however, antepartum stillbirths and postneonatal infant deaths ascribed to congenital abnormality were also increased across the range of deprivation and were not significantly attenuated by adjustment for maternal characteristics. These findings could indicate direct environmental causes of congenital abnormality in areas of high deprivation. They could also plausibly reflect differential use of antenatal screening and intervention for congenital anomalies.

When we compared the association between socioeconomic deprivation and the risk of stillbirth and infant death from causes other than sudden infant death syndrome, we found no strong evidence for changes in health inequalities over the four epochs. Analysis of other interaction terms between epoch and deprivation category showed one other association with $\mathrm{P}<0.05$-namely, postneonatal infant death from congenital abnormality. It is possible that this could reflect differential uptake of prenatal screening, which developed greatly over the period of study. There was, however, no evidence of any change in the relation between deprivation and other types of loss related to congenital anomaly (stillbirth or neonatal death). Moreover, while the $\mathrm{P}$ value for the interaction for sudden infant death syndrome was significant at $<0.001$, the value was much less extreme for postneonatal infant death from congenital abnormality (0.02). Our interpretation is that the apparent change in the association between deprivation and postneonatal infant death from congenital abnormality is most likely to be a chance finding because of the large number of statistical comparisons.

\section{Conclusion}

The rate of sudden infant death syndrome declined in Scotland in the early 1990s. The onset of the decline was earlier and the rate of decline was more rapid among women living in areas of low socioeconomic deprivation. The changes in the association between sudden infant death syndrome and deprivation are most plausibly explained by differential uptake of the recommended changes in infant sleeping position. The effect of this was to create a strong independent association between deprivation and sudden infant death syndrome where one did not exist before. There were no comparable changes in the association between deprivation and stillbirths or other causes of infant death.

Contributors: GCSS had the original idea. MF performed the record linkage and extracted the data. GCSS, DP, and AMW designed and performed the statistical analysis and drafted the paper. All authors contributed to editing the draft for content and edited and approved the final version of the paper. GCSS is guarantor.

Funding: The study was supported by the NIHR Cambridge Comprehensive Biomedical Research Centre. DP was funded by an MRC clinical training fellowship. The funding bodies had no role in any aspect of the conduct, analysis, or presentation of this study.

Competing interests: All authors have completed the ICMJE uniform disclosure form at www.icmje.org/coi_disclosure.pdf (available on request from the corresponding author) and declare: no support from any organisation for the submitted work; no financial relationships with any organisations that might have an interest in the submitted work in the previous three years; no other relationships or activities that could appear to have influenced the submitted work.

Ethical approval: The work was approved by the privacy advisory committee of the information services division of NHS Scotland. 


\section{What is already known on this topic}

Rates of sudden infant death syndrome fell rapidly throughout the world in the 1990s after recommendations that infants should not sleep prone

There is limited information on the timing and rate of decline in relation to socioeconomic deprivation

\section{What this study adds}

The decline in the rate of sudden infant death syndrome in Scotland in the 1990 s had a later onset and was slower among women living in areas of high deprivation

The effect was to create a strong independent association between deprivation and sudden infant death syndrome where one did not exist before

There were no comparable changes in relative inequalities for other causes of infant mortality or stillbirth

Data sharing: Requests for the raw data from this study should be made directly to the information services division of NHS Scotland.

World Health Organization. The global burden of disease 2004 update. WHO, 2008 Smith GC, Fretts RC. Stillbirth. Lancet 2007;370:1715-25.

3 Messer J. Statistical bulletin: gestation-specific infant mortality, 2007-2008. 1-7. Office for National Statistics, 2010

4 Guildea ZE, Fone DL, Dunstan FD, Sibert JR, Cartlidge PH. Social deprivation and the causes of stillbirth and infant mortality. Arch Dis Child 2001;84:307-10.

5 Beal S. Sleeping position and SIDS. Lancet 1988;ii:512.

6 Lee NN, Chan YF, Davies DP, Lau E, Yip DC. Sudden infant death syndrome in Hong Kong: confirmation of low incidence. BMJ 1989;298:721.

7 De Jonge GA, Engelberts AC, Koomen-Liefting AJ, Kostense PJ. Cot death and prone sleeping position in the Netherlands. BMJ 1989:298:722.

8 Fleming PJ, Gilbert R, Azaz Y, Berry PJ, Rudd PT, Stewart A, et al. Interaction between bedding and sleeping position in the sudden infant death syndrome: a population based case-control study. BMJ 1990;301:85-9.

9 Mitchell EA, Scragg R, Stewart AW, Becroft DM, Taylor BJ, Ford RP, et al. Results from the first year of the New Zealand cot death study. N Z Med J 1991;104:71-6.

10 Kinney HC, Thach BT. The sudden infant death syndrome. N Engl J Med 2009;361:795-805.

11 Blair PS, Sidebotham P, Berry PJ, Evans M, Fleming PJ. Major epidemiological changes in sudden infant death syndrome: a 20 -year population-based study in the UK. Lancet 2006;367:314-9.

12 Hey EN, Lloyd DJ, Wigglesworth JS. Classifying perinatal death: fetal and neonatal factors. Br J Obstet Gynaecol 1986;93:1213-23.
13 Information Services Division NHS Scotland. Scottish perinatal and infant mortality report. ISD Publications, Common Services Agency, 2008

14 Sadler DW. The value of a thorough protocol in the investigation of sudden infant deaths. $J$ Clin Pathol 1998:51:689-94.

15 Brooke H, Gibson A, Tappin D, Brown H. Case-control study of sudden infant death syndrome in Scotland, 1992-5. BMJ 1997;314:1516-20.

16 McLoone P, Boddy FA. Deprivation and mortality in Scotland, 1981 and 1991. BM 1994;309:1465-70

17 Little R, Rubin D. Statistical analysis with missing data. Wiley, 2008

18 Carpenter RG, Irgens LM, Blair PS, England PD, Fleming P, Huber J, et al. Sudden unexplained infant death in 20 regions in Europe: case control study. Lancet 2004;363:185-91.

19 Shipton D, Tappin DM, Vadiveloo T, Crossley JA, Aitken DA, Chalmers J. Reliability of self reported smoking status by pregnant women for estimating smoking prevalence: a retrospective, cross sectional study. BMJ 2009;339:b4347.

20 Blair PS, Sidebotham P, Evason-Coombe C, Edmonds M, Heckstall-Smith EM, Fleming P. Hazardous cosleeping environments and risk factors amenable to change: case-control study of SIDS in south west England. BMJ 2009;339:b3666.

Accepted: 25 January 2012

\section{Cite this as: BMJ 2012;344:e1552}

This is an open-access article distributed under the terms of the Creative Commons Attribution Non-commercial License, which permits use, distribution, and reproduction in any medium, provided the original work is properly cited, the use is non commercial and is otherwise in compliance with the license. See: http://creativecommons.org/licenses/by$\mathrm{nc} / 2.0 /$ and http://creativecommons.org/licenses/by-nc/2.0/legalcode. 


\section{Tables}

Table 1 | Diagnostic codes used for classification of infant death

\begin{tabular}{lcc} 
Cause of death $^{*}$ & ICD-9 & ICD-10 \\
Sudden infant death syndrome & 798.0 & R95 \\
\hline Congenital anomaly & $740.0-759.9$ & Q0-Q999 \\
\hline Infection & $001.0-139.0,320.0-326.0,390.0-392.0,460.0-466.1$, & A0-A990, BO-B990, G0-G099, I0-I019, I300-I339, \\
& $480.0-481.0$ & I390-I418, H60, H62, H65-67, J0-J329 \\
\hline
\end{tabular}

ICD=international classification of diseases.

*Diagnostic code had to be in principal position. Category "other" was defined as postneonatal death where none of above was listed in principal position on death certificate. 
Table 2| Maternal characteristics and outcomes in relation to socioeconomic deprivation category ( $\mathrm{n}=1355683$ ). Figures are numbers (percentage) unless stated otherwise

\begin{tabular}{|c|c|c|c|c|c|c|c|c|}
\hline & \multicolumn{7}{|c|}{ Socioeconomic deprivation category* } & \multirow[b]{2}{*}{ P value } \\
\hline & 1 & 2 & 3 & 4 & 5 & 6 & 7 & \\
\hline No (\%) & $72950(5.4)$ & $182014(13.4)$ & $278918(20.6)$ & $335622(24.8)$ & $214056(15.8)$ & $163094(12.0)$ & $109019(8.0)$ & \\
\hline $\begin{array}{l}\text { Mean (IQR) age } \\
\text { (years) } \ddagger\end{array}$ & $31(28-34)$ & $30(26-33)$ & $28(25-32)$ & $27(23-31)$ & $26(22-30)$ & $26(22-31)$ & $25(21-29)$ & $<0.001$ \\
\hline \multicolumn{9}{|l|}{ Paritył: } \\
\hline 0 & 30425 (41.9) & $82959(45.7)$ & $125096(45.0)$ & $153819(46.0)$ & $97001(45.5)$ & $73446(45.1)$ & $46994(43.2)$ & \multirow[t]{4}{*}{$<0.001$} \\
\hline $1-2$ & $38819(534)$ & $89856(49.5)$ & $136627(49.2)$ & $159445(47.7)$ & $100673(47.2)$ & $75686(46.5)$ & $50803(46.7)$ & \\
\hline $3-4$ & $3137(4.3)$ & $7827(4.3)$ & $14494(5.2)$ & $18696(5.6)$ & $13704(6.4)$ & $11763(7.2)$ & $9435(8.7)$ & \\
\hline$>4$ & $269(0.4)$ & $752(0.4)$ & $1727(0.6)$ & $2397(0.7)$ & $1955(0.9)$ & $1857(1.1)$ & $1611(1.5)$ & \\
\hline $\begin{array}{l}\text { Mean }(\text { IQR) } \\
\text { height }(\mathrm{cm}) \ddagger\end{array}$ & $163(159-168)$ & $163(159-168)$ & $163(158-167)$ & $162(158-167)$ & $162(157-166)$ & $161(157-165)$ & $160(156-165)$ & $<0.001$ \\
\hline Married $\ddagger$ & 57168 (87.5) & $133089(79.7)$ & $183100(71.9)$ & $196782(64.5)$ & $109955(57.4)$ & $76613(55.1)$ & 39646 (39.9) & $<0.001$ \\
\hline \multicolumn{9}{|l|}{ Smoking status $\ddagger \S:$} \\
\hline Non-smoker & 37343 (82.6) & $86802(75.0)$ & $115650(67.0)$ & $127230(60.2)$ & 73164 (55.7) & 55929 (55.2) & 26579 (45.5) & \multirow[t]{3}{*}{$<0.001$} \\
\hline Smoker & $4334(9.6)$ & $18497(16.0)$ & $39908(231)$ & $62656(29.7)$ & $46692(35.6)$ & $36898(36.4)$ & $27425(47.0)$ & \\
\hline Ex-smoker & $3540(7.8)$ & $10519(9.1)$ & $17055(9.9)$ & $21330(10.1)$ & $11443(8.7)$ & $8577(8.5)$ & $4400(7.5)$ & \\
\hline $\begin{array}{l}\text { Mean (IQR) } \\
\text { gestation (weeks) }\end{array}$ & $40(39-41)$ & $40(39-41)$ & $40(39-31)$ & $40(39-41)$ & $40(39-41)$ & $40(39-41)$ & $40(39-41)$ & $<0.001$ \\
\hline Preterm births & $3235(4.4)$ & $8913(4.9)$ & $14406(5.2)$ & $18947(5.7)$ & $13295(6.2)$ & $10211(6.3)$ & $8019(7.4)$ & $<0.001$ \\
\hline \multicolumn{9}{|c|}{ Hospital throughput: } \\
\hline$<1000$ & $2211(3.0)$ & $12947(7.1)$ & $36972(13.3)$ & $28898(8.6)$ & $8707(4.1)$ & $3898(2.4)$ & $815(0.8)$ & \multirow[t]{5}{*}{$<0.001$} \\
\hline $1000-999$ & $6063(8.3)$ & 36989 (20.3) & 70383 (25.2) & $73947(22.0)$ & $36610(17.1)$ & $16887(10.4)$ & $7017(6.4)$ & \\
\hline $2000-999$ & $15895(21.8)$ & $31583(17.4)$ & $54185(19.4)$ & 75985 (22.6) & $34315(16.0)$ & $37428(23.0)$ & $24608(22.6)$ & \\
\hline $3000-999$ & $18382(25.2)$ & 37287 (20.5) & $49939(17.9)$ & $76121(22.7)$ & $56273(26.3)$ & $73307(45.0)$ & $27595(25.3)$ & \\
\hline$\geq 4000$ & $30399(41.7)$ & $63209(34.7)$ & $67443(24.2)$ & $80676(24.0)$ & 78151 (36.5) & 31574 (19.4) & $48984(44.9)$ & \\
\hline \multicolumn{9}{|l|}{ Calendar year: } \\
\hline $1985-90$ & $19892(26.0)$ & $46090(23.5)$ & $72491(26.0)$ & $88128(26.3)$ & $59018(27.6)$ & $46279(28.4)$ & $35152(32.2)$ & \multirow[t]{4}{*}{$<0.001$} \\
\hline $1991-6$ & $19412(26.6)$ & $47819(26.3)$ & $74689(26.8)$ & $89124(26.6)$ & $57431(26.8)$ & $42312(25.9)$ & $28995(26.6)$ & \\
\hline $1997-2002$ & $17581(24.1)$ & $43983(24.2)$ & $66301(23.8)$ & $78424(23.4)$ & $49052(22.9)$ & $36687(22.5)$ & $22390(20.5)$ & \\
\hline $2003-8$ & $16995(23.3)$ & $44123(24.2)$ & 65441 (23.5) & 79951 (23.8) & 48555 (22.7) & $37816(23.2)$ & $22482(20.6)$ & \\
\hline $\begin{array}{l}\text { All stillbirth and } \\
\text { infant death }\end{array}$ & $436(0.6)$ & $1192(0.7)$ & $2044(0.7)$ & $2786(0.8)$ & $1921(0.9)$ & $1512(0.9)$ & $1167(1.1)$ & $<0.001$ \\
\hline \multicolumn{9}{|c|}{ Rates of loss per $10000(95 \% \mathrm{Cl})$} \\
\hline $\begin{array}{l}\text { All stillbirth and } \\
\text { infant death }\end{array}$ & $\begin{array}{c}59.8(54.4 \text { to } \\
65.6)\end{array}$ & $\begin{array}{c}65.5 \text { (61.9 to } \\
69.3)\end{array}$ & $\begin{array}{c}73.3(70.2 \text { to } \\
76.5)\end{array}$ & $\begin{array}{c}83.0(80.0 \text { to } \\
86.1)\end{array}$ & $\begin{array}{c}89.7 \text { (85.8 to } \\
93.8)\end{array}$ & $\begin{array}{c}92.7 \text { (88.2 to } \\
97.5)\end{array}$ & $\begin{array}{c}107.0(101.1 \text { to } \\
113.3)\end{array}$ & $<0.001$ \\
\hline $\begin{array}{l}\text { All antepartum } \\
\text { stillbirth }\end{array}$ & $\begin{array}{c}26.2(22.7 \text { to } \\
30.2)\end{array}$ & $\begin{array}{c}27.8(25.5 \text { to } \\
30.3)\end{array}$ & $\begin{array}{c}34.7 \text { (32.6 to } \\
37.0)\end{array}$ & $\begin{array}{c}37.6 \text { (35.6 to } \\
39.8)\end{array}$ & $\begin{array}{c}41.7 \text { (39.0 to } \\
44.5)\end{array}$ & $\begin{array}{c}42.8 \text { (39.7 to } \\
46.1)\end{array}$ & $\begin{array}{c}46.8 \text { (42.9 to } \\
51.0)\end{array}$ & $<0.001$ \\
\hline Congenital & 2.3 (1.4 to 3.7$)$ & 2.5 (1.8 to 3.3$)$ & 2.7 (2.1 to 3.4$)$ & $3.4(2.8$ to 4.1$)$ & 3.9 (3.1 to 4.8$)$ & 3.2 (2.4 to 4.2$)$ & 3.4 (2.5 to 4.7$)$ & $<0.001$ \\
\hline Explained & 7.0 (5.3 to 9.2$)$ & 8.3 (7.1 to 9.7$)$ & $9.8(8.7$ to 11.0$)$ & 10.7 (9.6 to 11.9 ) & $\begin{array}{c}12.8(11.3 \text { to } \\
14.4)\end{array}$ & $\begin{array}{c}12.5 \text { (10.9 to } \\
14.3)\end{array}$ & $\begin{array}{c}15.3(13.2 \text { to } \\
17.8)\end{array}$ & $<0.001$ \\
\hline $\begin{array}{l}\text { Unexplained, } \\
\text { SGA }\end{array}$ & 4.8 (3.4 to 6.7$)$ & 5.4 (4.5 to 6.6$)$ & $6.6(5.7$ to 7.7$)$ & 8.2 (7.3 to 9.2$)$ & 10.2 (8.9 to 11.6$)$ & 10.9 (9.4 to 12.6$)$ & $\begin{array}{c}12.9(11.0 \text { to } \\
15.3)\end{array}$ & $<0.001$ \\
\hline $\begin{array}{l}\text { Unexplained, } \\
\text { not SGA }\end{array}$ & $12.2(9.9$ to 15.0$)$ & $\begin{array}{c}11.6(10.2 \text { to } \\
13.3)\end{array}$ & $\begin{array}{c}15.7 \text { (14.3 to } \\
17.2)\end{array}$ & $\begin{array}{c}15.4(14.2 \text { to } \\
16.8)\end{array}$ & $\begin{array}{c}15.0(13.4 \text { to } \\
16.7)\end{array}$ & $\begin{array}{c}16.4(14.6 \text { to } \\
18.5)\end{array}$ & $\begin{array}{c}15.4(13.2 \text { to } \\
17.9)\end{array}$ & 0.002 \\
\hline $\begin{array}{l}\text { All intrapartum } \\
\text { stillbirth and } \\
\text { neonatal death }\end{array}$ & $\begin{array}{c}22.8(19.6 \text { to } \\
26.6)\end{array}$ & $\begin{array}{c}22.2(20.1 \text { to } \\
24.5)\end{array}$ & $\begin{array}{c}21.8(20.1 \text { to } \\
23.6)\end{array}$ & $\begin{array}{c}25.7 \text { (24.0 to } \\
27.5)\end{array}$ & $\begin{array}{c}26.4 \text { (24.3 to } \\
28.6)\end{array}$ & $\begin{array}{c}25.7 \text { (23.3 to } \\
28.3)\end{array}$ & $\begin{array}{c}26.8(23.9 \text { to } \\
30.1)\end{array}$ & $<0.001$ \\
\hline Congenital & $\begin{array}{c}12.4(10.1 \text { to } \\
15.2)\end{array}$ & 10.5 (9.1 to 12.1$)$ & 9.5 (8.4 to 10.7$)$ & $\begin{array}{c}11.3(10.2 \text { to } \\
12.5)\end{array}$ & $\begin{array}{c}12.1(10.7 \text { to } \\
13.6)\end{array}$ & 10.1 (8.7 to 11.8$)$ & $\begin{array}{c}13.5(11.4 \text { to } \\
15.8)\end{array}$ & 0.09 \\
\hline Preterm & 4.4 (3.1 to 6.2$)$ & 4.7 (3.8 to 5.8 ) & 5.9 (5.0 to 6.8$)$ & $6.2(5.4$ to 7.1$)$ & 6.5 (5.5 to 7.6$)$ & $7.9(6.6$ to 9.4$)$ & $7.6(6.1$ to 9.4$)$ & $<0.001$ \\
\hline Term & 6.0 (4.5 to 8.1$)$ & 7.1 (5.9 to 8.4$)$ & 6.4 (5.6 to 7.5$)$ & 8.2 (7.3 to 9.2$)$ & $7.8(6.7$ to 9.1$)$ & 7.7 (6.5 to 9.2$)$ & 5.8 (4.5 to 7.4$)$ & 0.48 \\
\hline
\end{tabular}


Table 2 (continued)

\begin{tabular}{|c|c|c|c|c|c|c|c|c|}
\hline & \multicolumn{7}{|c|}{ Socioeconomic deprivation category ${ }^{\star}$} & \multirow[b]{2}{*}{$\mathbf{P}$ value } \\
\hline & 1 & 2 & 3 & 4 & 5 & 6 & 7 & \\
\hline $\begin{array}{l}\text { All postneonatal } \\
\text { infant death }\end{array}$ & $10.9(8.7$ to 13.6$)$ & $\begin{array}{c}15.6(13.9 \text { to } \\
17.6)\end{array}$ & $\begin{array}{c}16.9(15.5 \text { to } \\
18.5)\end{array}$ & $\begin{array}{c}19.9(18.5 \text { to } \\
21.5)\end{array}$ & $\begin{array}{c}22.0(20.1 \text { to } \\
24.1)\end{array}$ & $\begin{array}{c}24.5(22.2 \text { to } \\
27.0)\end{array}$ & $\begin{array}{c}33.8(30.5 \text { to } \\
37.5)\end{array}$ & $<0.001$ \\
\hline Congenital & $2.6(1.7$ to 4.1$)$ & 4.8 (3.9 to 5.9$)$ & $4.2(3.5$ to 5.0$)$ & 4.5 (3.8 to 5.2$)$ & $4.9(4.0$ to 5.9$)$ & 5.9 (4.9 to 7.2$)$ & 7.7 (6.2 to 9.5$)$ & $<0.001$ \\
\hline Infection & $1.0(0.5$ to 2.0$)$ & $1.3(0.9$ to 2.0$)$ & $1.0(0.7$ to 1.5$)$ & $1.1(0.8$ to 1.6$)$ & $1.9(1.4$ to 2.6$)$ & 1.5 (1.0 to 2.2$)$ & 2.1 (1.4 to 3.2 ) & 0.008 \\
\hline Other & 3.7 (2.6 to 5.4$)$ & 4.3 (3.4 to 5.4$)$ & 4.7 (4.0 to 5.6$)$ & 5.8 (5.1 to 6.7$)$ & $6.2(5.2$ to 7.4$)$ & $6.3(5.2$ to 7.6$)$ & 6.7 (5.3 to 8.4$)$ & $<0.001$ \\
\hline SIDS & $3.6(2.4$ to 5.3$)$ & $5.2(4.2$ to 6.4$)$ & $7.0(6.1$ to 8.$)$ & 8.5 (7.5 to 9.5$)$ & $9.0(7.8$ to 10.4$)$ & 10.8 (9.3 to 12.5$)$ & $\begin{array}{c}17.4(15.1 \text { to } \\
20.0)\end{array}$ & $<0.001$ \\
\hline
\end{tabular}

$\mathrm{IQR}=$ interquartile range; $\mathrm{SGA}=$ small for gestational age; $\mathrm{SIDS}=$ sudden infant death syndrome.

*1=least deprived, $7=$ most deprived.

†Kruskal Wallis test, $\chi^{2}$ test, $\chi^{2}$ test for trend, and Mantel-Haenszel score test for trend as appropriate.

‡Numbers (\%) missing data: maternal age $24(<0.1)$, parity $4410(0.3)$, height 210369 (15.5), marital status 133898 (9.9), and smoking 519712 (38.3).

§Information on smoking available only from 1992, hence summary statistics for smoking are for records for 1992-2008. 


\begin{tabular}{|c|c|c|c|c|}
\hline \multicolumn{5}{|c|}{ Table 3| Cause specific perinatal and infant mortality and socioeconomic deprivation, Scotland 1992-2008 } \\
\hline & \multicolumn{4}{|c|}{ Odds ratio* $(95 \% \mathrm{Cl})$} \\
\hline & Unadjusted & Adjusted 1† & Adjusted $2 \dagger$ & Adjusted 3† \\
\hline \multicolumn{5}{|c|}{ Antepartum stillbirth $\ddagger$ (non-cases=922 040): } \\
\hline All $(n=3259)$ & $1.75(1.54$ to 1.98$)$ & $1.53(1.33$ to 1.75$)$ & $1.34(1.17$ to 1.54$)$ & - \\
\hline Congenital $(n=295)$ & $1.63(1.08$ to 2.46$)$ & 1.61 (1.04 to 2.48$)$ & $1.58(1.02$ to 2.45$)$ & - \\
\hline Explained $(n=899)$ & $2.11(1.66$ to 2.67$)$ & $1.71(1.31$ to 2.23$)$ & $1.37(1.05$ to 1.80$)$ & - \\
\hline Unexplained, SGA $(\mathrm{n}=687)$ & 2.99 (2.26 to 3.97$)$ & 2.56 (1.88 to 3.48$)$ & 2.01 (1.48 to 2.75$)$ & - \\
\hline $\begin{array}{l}\text { Unexplained, not SGA } \\
(\mathrm{n}=1378)\end{array}$ & $1.20(0.99$ to 1.46$)$ & 1.09 (0.89 to 1.35$)$ & $1.06(0.86$ to 1.30$)$ & - \\
\hline \multicolumn{5}{|c|}{ Intrapartum stillbirth and neonatal death (non-cases=920 126): } \\
\hline All $(n=1914)$ & $1.30(1.10$ to 1.54$)$ & $10.18(0.99$ to 1.41$)$ & $1.14(0.95$ to 1.37$)$ & 1.06 (0.89 to 1.28$)$ \\
\hline Congenital $(n=851)$ & $1.16(0.89$ to 1.50$)$ & $1.02(0.78$ to 1.34$)$ & $1.03(0.78$ to 1.34$)$ & 0.96 (0.73 to 1.26$)$ \\
\hline Preterm $(n=440)$ & $1.82(1.29$ to 2.58$)$ & 1.49 (1.03 to 2.14$)$ & $1.33(0.92$ to 1.93$)$ & $1.21(0.83$ to 1.79$)$ \\
\hline Term $(\mathrm{n}=623)$ & $1.21(0.91$ to 1.60$)$ & $1.23(0.90$ to 1.70$)$ & $1.19(0.86$ to 1.63$)$ & $1.20(0.87$ to 1.65$)$ \\
\hline \multicolumn{5}{|c|}{ Postneonatal infant death (non-cases=918 750): } \\
\hline All $(n=1376)$ & 2.94 (2.41 to 3.58$)$ & $1.90(1.53$ to 2.36$)$ & $1.63(1.31$ to 2.03$)$ & $1.56(1.25$ to 1.94$)$ \\
\hline Congenital‡ $(n=400)$ & $2.63(1.81$ to 3.81$)$ & $2.63(1.77$ to 3.92$)$ & $2.50(1.67$ to 3.74$)$ & - \\
\hline Infection $(\mathrm{n}=92)$ & $1.48(0.65$ to 3.36$)$ & $1.00(0.43$ to 2.34$)$ & $0.89(0.38$ to 2.10$)$ & 0.85 (0.36 to 2.03$)$ \\
\hline Other $(n=419)$ & $1.84(1.31$ to 2.58$)$ & $1.14(0.79$ to 1.66$)$ & $1.04(0.72$ to 1.50$)$ & 0.98 (0.68 to 1.43$)$ \\
\hline $\operatorname{SIDS}(n=465)$ & 5.70 (4.04 to 8.03$)$ & $2.62(1.76$ to 3.89$)$ & 2.00 (1.34 to 2.97$)$ & 1.93 (1.30 to 2.87$)$ \\
\hline \multicolumn{5}{|c|}{ Stillbirth and infant death $\ddagger$ (non-cases=918 750): } \\
\hline All $(n=6549)$ & 1.79 (1.64 to 1.96$)$ & $1.48(1.34$ to 1.64$)$ & $1.33(1.20$ to 1.47$)$ & - \\
\hline
\end{tabular}

SGA=small for gestational age; SIDS=sudden infant death syndrome.

${ }^{*}$ For six category change in socioeconomic deprivation to represent move from highest to lowest socioeconomic deprivation groups.

$\dagger 1=$ =adjusted for maternal age, height, parity, marital status and hospital throughput; $2=$ =additionally adjusted for maternal smoking; $3=$ additionally adjusted for gestational age.

$\ddagger$ Antepartum stillbirths and infant deaths from congenital abnormalities not adjusted for gestational age. 
Table 4| Temporal changes in relation between cause specific perinatal and infant mortality and socioeconomic deprivation, Scotland 1985-2008 (unadjusted)

\begin{tabular}{llll}
\multicolumn{5}{c}{ Odds ratio $^{*}(95 \% \mathrm{Cl})$} & \\
\cline { 1 - 3 } $1985-90$ & $1991-6$ & $1997-2002$ & $2003-8$
\end{tabular} P for interaction†

Antepartum stillbirth (non-cases $=1350655)$ :

\begin{tabular}{|c|c|c|c|c|c|}
\hline All $(n=5028)$ & $1.82(1.52$ to 2.19$)$ & $1.79(1.48$ to 2.16$)$ & $1.76(1.41$ to 2.20$)$ & 1.59 (1.26 to 1.99$)$ & 0.81 \\
\hline Congenital $(n=422)$ & $1.64(0.82$ to 3.25$)$ & $1.46(0.81$ to 2.63$)$ & $1.93(0.88$ to 4.22$)$ & 1.31 (0.66 to 2.59$)$ & 0.89 \\
\hline Explained $(n=1462)$ & 1.81 (1.30 to 2.52$)$ & $1.93(1.39$ to 2.70$)$ & 2.66 (1.77 to 3.99$)$ & 1.65 (1.02 to 2.68$)$ & 0.41 \\
\hline Unexplained SGA ( $n=1131)$ & 2.16 (1.59 to 3.07$)$ & $3.12(2.04$ to 4.77$)$ & 3.49 (2.15 to 5.67$)$ & $2.64(1.61$ to 4.34$)$ & 0.38 \\
\hline Unexplained, not SGA $(n=2013)$ & 1.65 (1.22 to 2.23$)$ & $1.30(0.97$ to 1.75$)$ & 0.95 (0.68 to 1.33$)$ & $1.28(0.92$ to 1.79$)$ & 0.13 \\
\hline \multicolumn{6}{|c|}{ Intrapartum stillbirth and neonatal death (non-cases=1 347 351): } \\
\hline All $(n=3304)$ & 1.08 (0.88 to 1.32$)$ & $1.36(1.07$ to 1.72$)$ & $1.30(0.97$ to 1.76$)$ & $1.32(0.96$ to 1.83$)$ & 0.45 \\
\hline Congenital $(n=1490)$ & $1.10(0.81$ to 1.49$)$ & $1.29(0.90$ to 1.84$)$ & $0.80(0.50$ to 1.28$)$ & 1.38 (0.84 to 2.26$)$ & 0.35 \\
\hline Preterm $(n=835)$ & 1.38 (0.95 to 2.02$)$ & 2.12 (1.31 to 3.43$)$ & 2.37 (1.28 to 4.40$)$ & $1.34(0.70$ to 2.56$)$ & 0.31 \\
\hline Term $(n=979)$ & $0.78(0.53$ to 1.14$)$ & $1.05(0.70$ to 1.57$)$ & 1.59 (0.98 to 2.57$)$ & $1.24(0.70$ to 2.20$)$ & 0.14 \\
\hline \multicolumn{6}{|c|}{ Postneonatal infant death (non-cases $=1344$ 625): } \\
\hline All $(n=2726)$ & 1.75 (1.42 to 2.15$)$ & 3.26 (2.45 to 4.33$)$ & $3.84(2.73$ to 5.40$)$ & $1.86(1.27$ to 2.71$)$ & $<0.001$ \\
\hline $\operatorname{SIDS}(n=1150)$ & 2.04 (1.53 to 2.72$)$ & $7.52(4.62$ to 12.25$)$ & 9.50 (5.46 to 16.53$)$ & 1.78 (0.87 to 3.65$)$ & $<0.001$ \\
\hline Congenital $(n=654)$ & $1.08(0.65$ to 1.79$)$ & $2.89(1.73$ to 4.84$)$ & $2.68(1.35$ to 5.30$)$ & 2.19 (1.07 to 4.49$)$ & 0.04 \\
\hline Infection $(n=185)$ & 3.05 (1.42 to 6.56$)$ & $1.52(0.55$ to 4.22$)$ & 0.48 (0.10 to 2.25$)$ & $2.71(0.48$ to 15.40$)$ & 0.19 \\
\hline Other $(n=737)$ & 1.53 (0.99 to 2.36$)$ & $1.47(0.87$ to 2.48$)$ & 2.69 (1.50 to 4.82$)$ & 1.60 (0.89 to 2.89$)$ & 0.39 \\
\hline \multicolumn{6}{|c|}{ Stillbirth and infant death (non-cases=1344 625): } \\
\hline All $(n=11058)$ & 1.53 (1.37 to 1.72$)$ & 1.87 (1.64 to 2.13 ) & 1.92 (1.64 to 2.25$)$ & $1.56(1.32$ to 1.84$)$ & 0.04 \\
\hline
\end{tabular}

$\mathrm{SGA}=$ small for gestational age; SIDS=sudden infant death syndrome.

${ }^{*}$ For six category change in socioeconomic deprivation to represent move from lowest to highest socioeconomic deprivation groups.

†Test of null hypothesis that association between socioeconomic deprivation category and type of death did not vary in four epochs studied. 
Table 5| Temporal changes in relation between cause specific perinatal and infant mortality and socioeconomic deprivation, Scotland 1985-2008 (*adjusted)

\begin{tabular}{llll}
\multicolumn{5}{c}{ Odda ratio† $(95 \% \mathrm{Cl})$} & \multirow{2}{*}{ P for interaction $\neq$}
\end{tabular}

Antepartum stillbirth (non-cases $=1350$ 655):

\begin{tabular}{|c|c|c|c|c|c|}
\hline All $(n=5028)$ & $1.47(1.22$ to 1.78$)$ & 1.51 (1.24 to 1.84$)$ & $1.48(1.18$ to 1.86$)$ & $1.38(1.10$ to 1.74$)$ & 0.95 \\
\hline Congenital $(n=422)$ & $1.34(0.66$ to 2.71$)$ & $1.32(0.69$ to 2.56$)$ & 1.74 (0.83 to 3.62$)$ & $1.26(0.61$ to 2.64$)$ & 0.93 \\
\hline Explained $(n=1462)$ & $1.36(0.98$ to 1.90$)$ & 1.51 (1.07 to 2.12$)$ & 2.05 (1.33 to 3.17$)$ & 1.34 (0.83 to 2.16$)$ & 0.46 \\
\hline Unexplained SGA ( $n=1131)$ & 1.61 (1.11 to 2.36$)$ & 2.42 (1.59 to 3.69$)$ & 2.77 (1.68 to 4.57$)$ & 2.26 (1.37 to 3.74$)$ & 0.29 \\
\hline Unexplained, not SGA $(n=2013)$ & 1.46 (1.07 to 2.00$)$ & $1.20(0.87$ to 1.65$)$ & $0.86(0.61$ to 1.23$)$ & $1.18(0.84$ to 1.66$)$ & 0.17 \\
\hline \multicolumn{6}{|c|}{ Intrapartum stillbirth and neonatal death (non-cases=1 347 351): } \\
\hline All $(n=3304)$ & $0.92(0.74$ to 1.13$)$ & 1.20 (0.95 to 1.52$)$ & $1.15(0.89$ to 1.55$)$ & 1.19 (0.86 to 1.65$)$ & 0.29 \\
\hline Congenital $(n=1490)$ & $0.92(0.67$ to 1.26$)$ & $1.13(0.81$ to 1.58$)$ & $0.70(0.44$ to 1.11$)$ & 1.22 (0.74 to 2.03$)$ & 0.29 \\
\hline Preterm $(n=835)$ & 0.99 (0.67 to 1.47$)$ & $1.62(0.99$ to 2.64$)$ & 1.78 (0.96 to 3.30$)$ & 1.07 (0.55 to 2.09 ) & 0.26 \\
\hline Term $(n=979)$ & 0.77 (0.51 to 1.19$)$ & 1.05 (0.67 to 1.63$)$ & $1.62(0.96$ to 2.74$)$ & 1.29 (0.74 to 2.26$)$ & 0.15 \\
\hline \multicolumn{6}{|c|}{ Postneonatal infant death (non-cases $=1344$ 625): } \\
\hline All $(n=2726)$ & $1.05(0.85$ to 1.30$)$ & $1.95(1.46$ to 2.61$)$ & 2.34 (1.65 to 3.32$)$ & $1.14(0.78$ to 1.69$)$ & $<0.001$ \\
\hline $\operatorname{SIDS}(n=1150)$ & $0.99(0.73$ to 1.34$)$ & $3.58(2.19$ to 5.85$)$ & $4.68(2.57$ to 8.56$)$ & $0.82(0.40$ to 1.70$)$ & $<0.001$ \\
\hline Congenital $(n=654)$ & $0.90(0.55$ to 1.47$)$ & 2.45 (1.45 to 4.15$)$ & 2.35 (1.22 to 4.52$)$ & 2.04 (0.98 to 4.24$)$ & 0.02 \\
\hline Infection $(n=185)$ & $1.70(0.74$ to 3.91$)$ & $0.85(0.31$ to 2.34$)$ & $0.26(0.05$ to 1.21$)$ & $1.61(0.31$ to 8.27$)$ & 0.16 \\
\hline Other $(n=737)$ & 0.98 (0.63 to 1.52$)$ & $0.94(0.53$ to 1.67$)$ & $1.73(0.92$ to 3.24$)$ & $1.06(0.56$ to 1.99$)$ & 0.45 \\
\hline \multicolumn{6}{|c|}{ Stillbirth and infant death (non-cases=1344 625): } \\
\hline All $(n=11058)$ & 1.17 (1.04 to 1.32$)$ & $1.47(1.28$ to 1.68$)$ & 1.51 (1.28 to 1.77$)$ & $1.26(1.07$ to 1.50$)$ & 0.02 \\
\hline
\end{tabular}

$\mathrm{SGA}=$ small for gestational age; SIDS=sudden infant death syndrome.

*Adjusted for maternal age, height, parity, marital status, and hospital throughput.

†For six category change in socioeconomic deprivation to represent move from highest to lowest socioeconomic deprivation groups.

$\ddagger$ Test of null hypothesis that association between socioeconomic deprivation category and type of death did not vary in four epochs studied. 
Table 6| Temporal changes in relation between cause specific perinatal and infant mortality and socioeconomic deprivation, Scotland 1985-2008, including linked and unlinked records (unadjusted)

\begin{tabular}{|c|c|c|c|c|c|}
\hline & \multicolumn{4}{|c|}{ Odds ratio* $(95 \% \mathrm{Cl})$} & \multirow[b]{2}{*}{$\mathbf{P}$ for interaction $\uparrow$} \\
\hline & $1985-90$ & 1991-6 & 1997-2002 & 2003-8 & \\
\hline \multicolumn{6}{|c|}{ Antepartum stillbirth (non-cases=1350 806): } \\
\hline All $(n=5378)$ & 1.81 (1.51 to 2.18$)$ & 1.84 (1.53 to 2.22$)$ & 1.93 (1.56 to 2.39$)$ & $1.77(1.43$ to 2.20$)$ & 0.96 \\
\hline Congenital $(n=462)$ & 1.70 (0.86 to 3.36$)$ & $1.50(0.84$ to 2.67$)$ & 2.03 (0.97 to 4.25$)$ & 1.08 (0.57 to 2.04$)$ & 0.62 \\
\hline Explained $(n=1569)$ & $1.78(1.28$ to 2.47$)$ & $2.05(1.48$ to 2.85$)$ & $3.07(2.07$ to 4.54$)$ & $1.63(1.03$ to 2.58$)$ & 0.12 \\
\hline Unexplained SGA $(n=1131)$ & 2.16 (1.53 to 3.07$)$ & 3.12 (2.04 to 4.77$)$ & 3.49 (2.15 to 5.67$)$ & 2.64 (1.61 to 4.34$)$ & 0.38 \\
\hline Unexplained, not SGA $(n=2216)$ & 1.66 (1.23 to 2.24$)$ & $1.32(0.99$ to 1.77$)$ & $1.10(0.80$ to 1.52$)$ & 1.75 (1.29 to 2.39$)$ & 0.14 \\
\hline \multicolumn{6}{|c|}{ Intrapartum stillbirth and neonatal death (non-cases=1 347 370): } \\
\hline All $(n=3435)$ & 1.07 (0.88 to 1.31$)$ & $1.31(1.04$ to 1.65$)$ & $1.32(0.99$ to 1.77$)$ & $1.30(0.96$ to 1.77$)$ & 0.43 \\
\hline Congenital $(n=1533)$ & $1.09(0.80$ to 1.47$)$ & $1.28(0.90$ to 1.81$)$ & $0.82(0.52$ to 1.30$)$ & $1.43(0.89$ to 2.30$)$ & 0.34 \\
\hline Preterm $(n=923)$ & 1.35 (0.93 to 1.96$)$ & $1.80(1.13$ to 2.87$)$ & $2.38(1.33$ to 4.24$)$ & $1.22(0.70$ to 2.12$)$ & 0.25 \\
\hline Term $(n=979)$ & $0.79(0.54$ to 1.16$)$ & 1.05 (0.70 to 1.57$)$ & 1.56 (0.96 to 2.52$)$ & 1.24 (0.70 to 2.20$)$ & 0.14 \\
\hline \multicolumn{6}{|c|}{ Postneonatal infant death (non-cases=1 344 633): } \\
\hline All $(n=2866)$ & 1.75 (1.43 to 2.14$)$ & 3.33 (2.52 to 4.40$)$ & 4.01 (2.86 to 5.62$)$ & $2.03(1.41$ to 2.93$)$ & $<0.001$ \\
\hline $\operatorname{SIDS}(n=1207)$ & 2.02 (1.53 to 2.67$)$ & $7.57(4.71$ to 12.16$)$ & $9.30(5.38$ to 16.07$)$ & $1.80(0.90$ to 3.58$)$ & $<0.001$ \\
\hline Congenital $(\mathrm{n}=682)$ & $1.11(0.68$ to 1.81$)$ & 2.84 (1.70 to 4.73$)$ & 2.94 (1.48 to 5.84$)$ & $2.63(1.32$ to 5.24$)$ & 0.03 \\
\hline Infection $(\mathrm{n}=191)$ & $3.06(1.45$ to 6.46$)$ & 1.44 (0.54 to 3.87$)$ & 0.66 (0.14 to 3.18$)$ & $2.70(0.48$ to 15.40$)$ & 0.30 \\
\hline Other $(n=786)$ & $1.53(1.01$ to 2.33$)$ & 1.65 (0.99 to 2.76$)$ & $2.80(1.57$ to 5.00$)$ & $1.77(1.00$ to 3.14$)$ & 0.40 \\
\hline \multicolumn{6}{|c|}{ Stillbirth and infant death (non-cases=1 344 633): } \\
\hline All $(n=11680)$ & $1.53(1.37$ to 1.72$)$ & 1.89 (1.66 to 2.15$)$ & 2.03 (1.74 to 2.37$)$ & $1.68(1.43$ to 1.96$)$ & 0.02 \\
\hline
\end{tabular}

$\mathrm{SGA}=$ small for gestational age; SIDS =sudden infant death syndrome.

${ }^{*}$ For six category change in socioeconomic deprivation to represent move from highest to lowest socioeconomic deprivation groups.

†Test of null hypothesis that association between socioeconomic deprivation category and type of death did not vary in four epochs studied. 


\section{Figures}

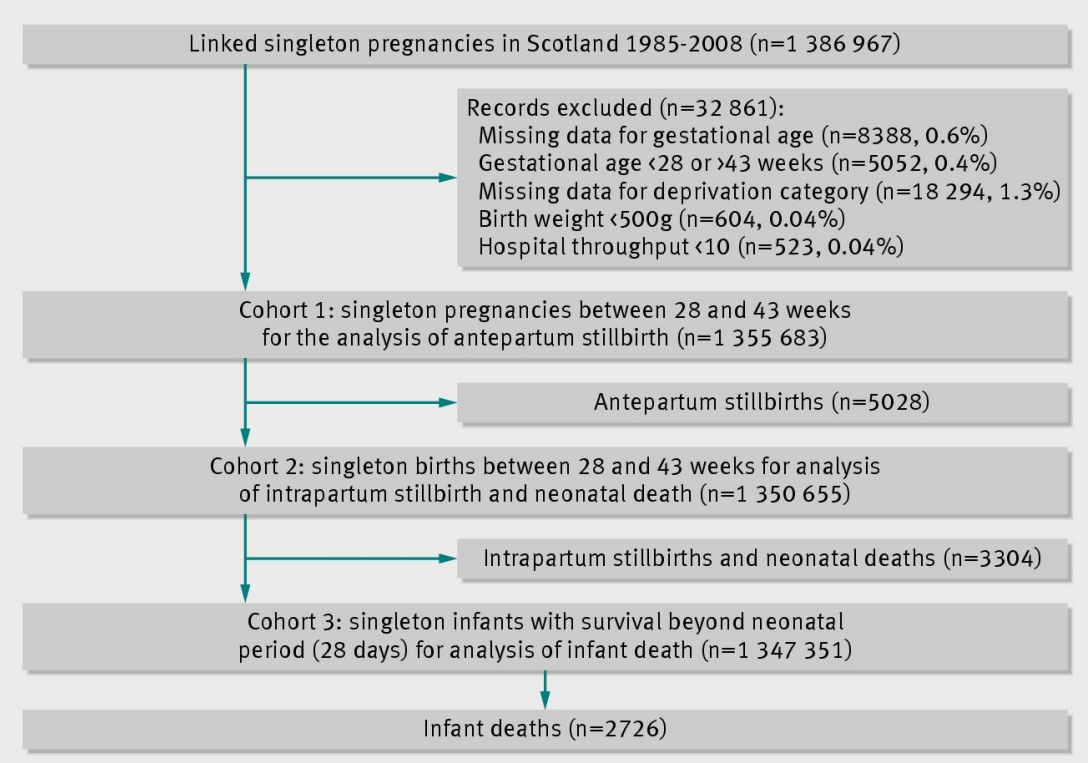

Fig 1 Selection of cohort and denominators for analyses in study of trends in socioeconomic inequalities in risk of infant mortality

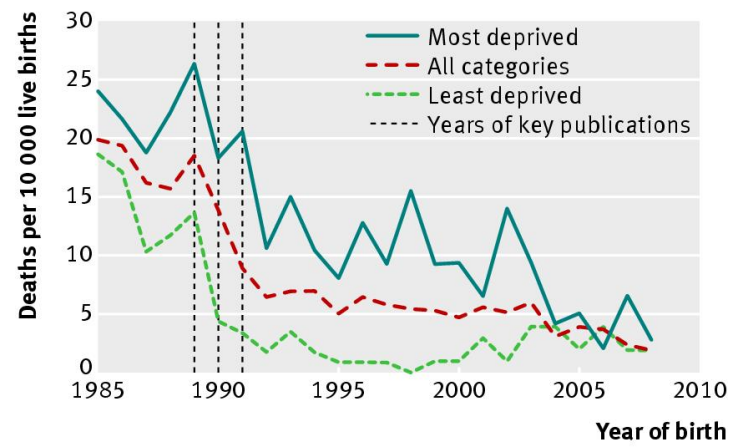

Fig 2 Rates of postneonatal infant death from sudden infant death syndrome in relation to year of birth, for all deprivation categories and most deprived (category 6 and 7) and least deprived (category 1 and 2) areas 